\title{
Effects of early life adverse experiences on the brain: implications from maternal separation models in rodents
}

\section{Mayumi Nishi *, Noriko Horii-Hayashi and Takayo Sasagawa}

Department of Anatomy and Cell Biology, Nara Medical University, Kashihara, Japan

\section{Edited by:}

Tomoko Soga, Monash University

Sunway Campus, Malaysia, Malaysia

Reviewed by:

David Walker, Ritchie Centre,

Australia

Kumi Kuroda, RIKEN, Japan

*Correspondence:

Mayumi Nishi, Department of Anatomy and Cell Biology, Faculty of

Medicine, Nara Medical University,

Kashihara, Nara 634-8521, Japan

e-mail: nmayumi@naramed-u.ac.jp
During postnatal development, adverse early life experiences affect the formation of neuronal networks and exert long-lasting effects on neural function. Many studies have shown that daily repeated maternal separation (MS), an animal model of early life stress, can regulate the hypothalamic-pituitary-adrenal axis (HPA axis) and affect subsequent brain function and behavior during adulthood. However, the molecular basis of the long-lasting effects of early life stress on brain function has not been fully elucidated. In this mini review, we present various cases of MS in rodents and illustrate the alterations in HPA axis activity by focusing on corticosterone (CORT). We then show a characterization of the brain regions affected by various patterns of MS, including repeated MS and single time MS at various stages before weaning, by investigating c-Fos expression. These CORT and c-Fos studies suggest that repeated early life stress may affect neuronal function in region- and temporal-specific manners, indicating a critical period for habituation to early life stress. Next, we introduce how early life stress can impact behavior, namely by inducing depression, anxiety or eating disorders, and alterations in gene expression in adult mice subjected to MS.

Keywords: maternal separation, HPA axis, depression, corticosteroid, gene expression, behavior, epigenetics

\section{INTRODUCTION}

As our contemporary society changes rapidly, changes in family structure can have a large influence on the mother-child relationship, as well as on other social environmental factors. In adult patients with various neuropsychiatric disorders, childhood abuse including sexual and/or physical abuse and neglect, is one of the most serious causes (Bremne and Vermetten, 2001; Heim and Nemeroff, 2001; Teicher et al., 2006). Adverse experiences occurring during critical periods of development, such as perinatal life, harmfully influence behavior, and physiological functions, including growth, metabolism, reproduction, and immune responses. Stressful environments in early life may induce permanent rather than transient consequences in animals. Previous studies have indicated that early unfavorable events augment the risk of behavioral disorders in adulthood, including neuropsychiatric disorders, such as depression (Kendler et al., 2002) and psychosis (Morgan et al., 2007). In rodent and primate models, adverse environments during the neonatal periods seem to play a critical role in developing the brain systems important to regulate behavior and stress responsiveness. In particular, the responsiveness of the hypothalamic-pituitary-adrenal (HPA) axis can be deteriorated by interrupting usual mother-pup interactions, which may induce persistent changes in the neurobiology, physiology, and emotional behavior in adult animals (Ellenbroek et al., 1998; Lyons et al., 1998; Pryce et al., 2005; Enthoven et al., 2008; Nishi et al., 2013).

In this mini review, we will focus on the response of corticosterone (CORT), an end product of the HPA axis in rodents, and $\mathrm{c}$-Fos expression for examining the activated brain regions induced by maternal separation (MS), a model of rodent early life stress. Furthermore, we will also present alterations of behavioral aspects and alterations in gene expression.

\section{EARLY MS}

The inventive studies of Levine and colleagues, and consequently of Meaney, Plotsky, and their collaborators have demonstrated that changes in rodents' early postnatal experiences can induce profound long-lasting effects on emotionality and stress response (Levine, 1967; Meaney, 2001; Plotsky et al., 2005), which have spurred the employment of the rodent MS for investigating early life stress. This early life stress model is based on the evidence that unfavorable events in early life cause the vulnerability for developing various kinds of diseases in later life. In this type of study, MS should be carefully discussed in comparison to the appropriate control group, which may or may not be undisturbed from mother.

The procedure of MS showed a variety of the duration (e.g., $60 \mathrm{~min}-24 \mathrm{~h}$ ) and the number of days (e.g., 1-14 days, 15-21 days) for the separation experiences among laboratories (Biagini et al., 1998; Caldji et al., 2000; Barreau et al., 2004; Arborelius and Eklund, 2007; Carrera et al., 2009; Tjong et al., 2010). In MS paradigm, many experiments, but certainly not all, have demonstrated that separation of pups from their mothers during the early postnatal period permanently increased anxiety-like behaviors in adulthood (Francis et al., 1999; Huot et al., 2001, 2004; Menard et al., 2004). As to the HPA axis activity, the response to stress is relatively low during early postnatal life (Walker et al., 1991; Levine, 2005), while MS could lead to life-long 
hyperactivity of the HPA axis (Holmes et al., 2005; Lippmann et al., 2007; Aisa et al., 2008; Marais et al., 2008). In contrast, short-term disturbance (e.g., $15 \mathrm{~min}$ ), which has been called "handling," appeared to reduce anxiety-like behaviors, decrease HPA axis tone and reduce the response to stress in adulthood (Levine, 2005; Plotsky et al., 2005). The process of handling may imitate natural mice rearing, whereby the mother leaves her pups for short periods of time to collect foods. Thus, the short-term MS, handling, might be considered a more natural event.

The effect of MS also varies depending upon whether pups are separated in a group of littermates during MS or isolated singly. Miyazaki and colleagues recently reported that rat pups isolated singly from the mother during PND7 to PND11 presented disturbance of cortical function, whereas pups separated but gathered from PND7 to PND11 showed no cortical disruption (Miyazaki et al., 2012).

\section{CHARACTERIZATION OF MATERNALLY SEPARATED ANIMALS SERUM LEVEL OF CORT}

In rodents, there is an unique period during which the HPA axis shows a rapid regression known as the stress hyporesponsive period (SHRP) (Levine, 2001). This period extends from PND4 to PND14 in rats and from PND2 to PND12 in mice. During the course of SHRP, ACTH in increased and baseline plasma glucocorticoid levels are lower than normal (Rosenfeld et al., 1991). Because, during ontogeny, the maintenance of low and stable levels of CORT is necessary for normal growth and development of the central nervous system (CNS), the SHRP is hypothesized to be neuroprotective against stress-induced excessive stimulation of glucocorticoid receptors (GRs) (Sapolsky and Meaney, 1986; Sapolsky, 1996). In rodents, the presence of the mother appears to suppress HPA axis activity, which primarily preserves the SHRP. Indeed, even during the SHRP, MS is a compelling inducer of a stress response. Meaney and his colleagues suggest that the quality of the mother-pup interactions, such as increased maternal licking, grooming, and arched-back nursing, is an important aspect for the preservation of this dampened HPA axis activity (Francis et al., 1999). The disturbance of SHRP induced by MS could cause an excessive exposure of the brain to high concentrations of glucocorticoids and activation of GRs, which may subsequently regulate brain and behavior in later life. Enhanced secretion of stress-induced CORT was observed in pups separated from their mothers for $1 \mathrm{~h}$ on PND2 to PND9 (McCormick et al., 1998). Nevertheless, a recent study indicated that repeated MS for $8 \mathrm{~h}$ daily from PND3 to PND5 rapidly desensitized the HPA axis activity of neonatal mice (Enthoven et al., 2008). We also reported that repeated MS for $3 \mathrm{~h}$ daily from PND1 to PND14 did not elevate a baseline level of CORT on PND14, whereas a single-time MS for $3 \mathrm{~h}$ at PND14 raised a baseline CORT level (Figure 1) (Horii-Hayashi et al., 2013). In contrast to the effects of MS on neonatal animals, repeated MS for $3 \mathrm{~h}$ daily from PND1 to PND14 significantly raises a CORT level in adulthood, as reported by many studies (Ryu et al., 2008; Jahng et al., 2010; Horii-Hayashi et al., 2013).

\section{ACTIVATED BRAIN REGIONS ANALYZED BY c-FOS EXPRESSION}

The expression of the immediate early gene product c-Fos is a reliable molecular marker to investigate neuronal activation. The examination of c-Fos expression has revealed that many brain regions are activated by MS, which differs depending on age and the type of stress. We recently analyzed the c-Fos expression induced by repeated MS and single-time MS during different developmental stages and time periods. Mice were exposed to $3 \mathrm{~h}$ repeated MS daily from PND1 to PND14 or from PND14 to PND21, or to single-time MS at PND14 or PND21 (Horii-Hayashi et al., 2013). We clarified that MS activated many brain regions and that c-Fos expression patterns



FIGURE 1 | Plasma CORT levels of repeated maternal separation (RMS) and single-time maternal separation (SMS) mice on PND14 and PND21 (Horii-Hayashi et al., 2013). The graphs show plasma CORT concentrations of PND14 (A) and PND21 (B) $(n=5-9$

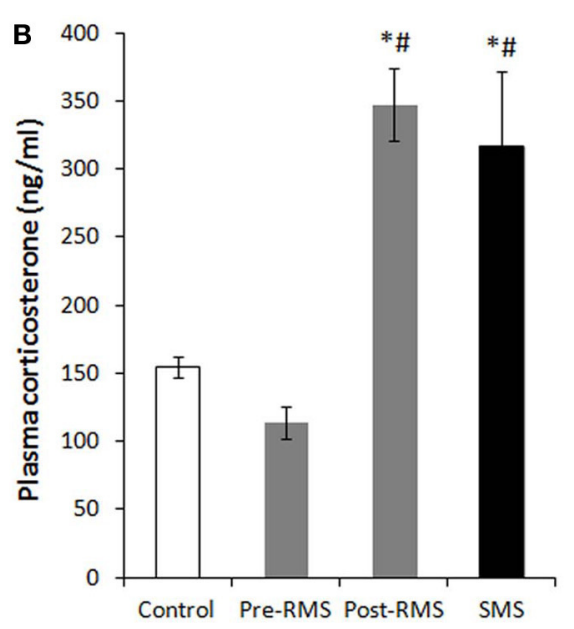

for each group). Blood samples were collected before (pre-RMS) and after (post-RMS) the final separation from RMS mice and after the separation from SMS mice. ${ }^{*} P<0.05$ vs. control, ${ }^{\#} P<0.05$ vs. Pre-MS. 
changed developmentally (Figure 2). Single-time MS at both ages activated many regions of the hypothalamus and limbic forebrain, while the pattern of c-Fos expression in the repeated MS groups were significantly different on PND14 and PND21. In repeated MS of PND14 mice, the c-Fos expression levels in many regions were markedly increased compared with age-matched controls, excepting the VMH, Arc, BST, DG, Ce, MePV, and MePD. By contrast, in repeated MS on PND21 mice, c-Fos expression was reduced to control levels in all observed brain regions except for the LS and CA3. These findings suggest that repetition of a homotypic stimulus suppresses c-Fos expression by PND21, but that such suppression is barely observed on PND14. Moreover, in animals exposed to repeated homotypic stress during the postnatal period, increase in adrenal CORT secretion does not always associate with increased c-Fos expression in the PVN. Such developmental differences in c-Fos expression detected in the repeated MS groups may be associated with a developmental critical period for stress responses involving the
HPA axis, during which animals are more susceptible to MS and other environments. In rodents, the critical period is the first two postnatal weeks. Thus, in early life, a repeated stress will be unlikely to suppress c-Fos expression. In turn, inappropriately activated c-Fos target genes may drastically alter how neurons function in critical neural circuits. Indeed, the suppression of increased c-Fos expression in repeated MS of PND14 mice was observed in specific regions (BST, Ce, MePD, and MePV) that form anatomical neural connections. These regions are referred to as an extended amygdala, which are closely associated with anxiety, fear, and psychiatric disorders (Davis et al., 2010). Therefore, even at PND14, repeated homotypic stress may reduce neural activity in the circuit of the extended amygdala. Moreover, in the SFO, where neurons are influenced by osmolality, calcium, and sodium concentrations in the systemic circulation (Smith and Ferguson, 2010), c-Fos expression was increased in both repeated and single-time MS mice, as compared to controls, on PND14. However, there were no changes in any of the groups

\section{A $\square$ Cont $\square$ RMS $\square$ SMS}
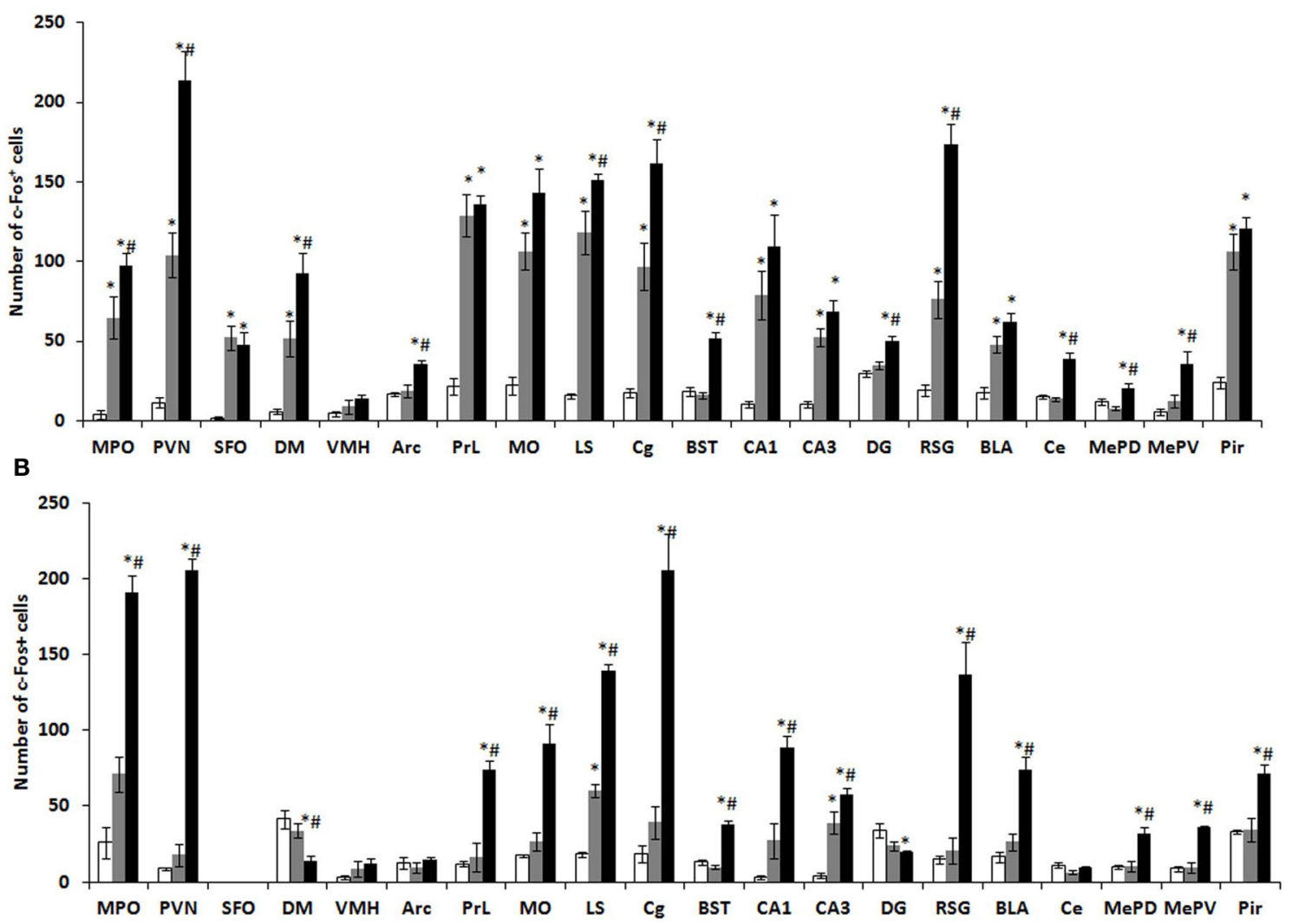

FIGURE 2 | c-Fos expression in the hypothalamus and limbic forebrain after MS (Horii-Hayashi et al., 2013). The graphs show the numbers of c-Fos-positive cells on PND14 (A) and PND21 (B) in non-separated control (white bar), RMS (gray bar), and SMS (black bar) mice ( $n=4-5$ for each group). In both RMS and SMS, the sampling point is just after MS procedure. ${ }^{*} P<0.05$ vs. control; ${ }^{\#} P<0.05$ vs. RMS. MPO, medial preoptic area; PVN, paraventricular nucleus; SFO, subfornical organ; DM, dorsomedial hypothalamic nucleus; $\mathrm{VMH}$, ventromedial hypothalamic nucleus; PrL, prelimbic cortex; MO, medial orbital cortex; LS, lateral septum; Cg, cingulate cortex; BST, bed nucleus of stria terminalis; CA1, hippocampal area CA1; CA3, hippocampal area CA3; DG, dentate gyrus; RSG, retrosplenial granular cortex; La, lateral amygdaloid nucleus; BLA, anterior part of the basolateral amygdaloid nucleus; $\mathrm{Ce}$, central amygdaloid nucleus; MePD, posterodorsal part of the medial amygdaloid nucleus; MePV, posteroventral part of the medial amygdaloid nucleus; Pir, piriform cortex. 
on PND21. This difference may reflect the increased resistance of physical growth to the hyperosmolality induced by deprivation of lactation.

\section{BEHAVIORAL CHANGES INDUCED BY MS IN RODENTS}

Early life adverse experiences including MS is one of the greatest contributing factors for mental health problems across life stages (Levine, 2005), relating not only to risk for mental health disorders but also to transdiagnostic features common in many psychological disorders (Glaser et al., 2006). I will introduce some of the behavioral aspects observed in animal model of MS.

\section{Depression- and anxiety-like behaviors}

Numerous studies have demonstrated a strong relationship between traumatic events during early life and development of behavioral abnormalities later in life. Early life adversity, such as that induced by MS, child physical, sexual, and emotional abuse, and general neglect has been linked to serious psychiatric impairment in adulthood (MacMillan et al., 2001). Particularly, a stressful life event such as early parental loss is associated with unipolar and bipolar depression, as well as anxiety disorders, beyond familial or genetic factors (Kendler et al., 1992; Agid et al., 1999; Furukawa et al., 1999; Heim and Nemeroff, 2001). Many human studies have reported that major depression and anxiety disorders are frequent in adults with a history of childhood abuse (Stein et al., 1996; Felitti et al., 1998). There have been numerous reports of the behavioral changes induced by MS in animal studies. Neonatal MS induces permanent alterations in the characteristics of the HPA response to stress in the offspring later in life (Ladd et al., 1996; Vazquez et al., 2000). Many studies of repeated MS during the first 2 weeks of neonatal life showed depression- and anxiety-like behaviors in adulthood (Newport et al., 2002; Daniels et al., 2004; Lee et al., 2007; Ryu et al., 2009). In these studies, ambulation and rearing decreased, immobility during a forced swim test increased, and time spent in the closed arms of an elevated plus maze increased.

\section{Fear response}

Until recently, no one had investigated how early experiences affected fear retention and extinction development, although these forms of emotional learning could be critically involved in the pathogenesis and treatment of mental health problems. Recent several studies showed that the timing of the maturation of fear learning is not set in static, but can be dynamically regulated by early experiences. Although the exact mechanisms are still unknown, when rats are reared under stressful conditions then they exhibit adult-like fear retention and extinction behaviors at an earlier stage of development (Callaghan et al., 2013). Chocyk et al. reported that MS decreased freezing time in both contextual and auditory fear conditioning in adolescent and adult rats (Chocyk et al., 2014). These results suggest that early life stress may permanently affect fear learning and memory.

\section{Food intake and response to food deprivation}

Previous studies showed that repeated MS during the first 2 weeks after birth may not permanently affect food intake and body weight gain of the offspring as long as the pups are reared in a group (Iwasaki et al., 2000; Kalinichev et al., 2002; Ryu et al., 2008). In contrast, post-weaning social isolation promotes food intake and weight gain of adolescent MS pups, with impacts on anxiety-like behaviors (Ryu et al., 2008). Anhedonia to palatable food, one of the major symptoms of depression, was reported in adolescent MS pups with disruption of the mesolimbic dopaminergic activity in response to stress (Noh et al., 2008). Another study showed that sustained hyperphagia observed in the MS pups subjected to a fasting/re-feeding cycle repeated during adolescent period of MS pups induced a binge-like eating disorder, in which increased activity of the HPA axis responding to such metabolic challenges appeared to play a role, at least partly, in mediation with the hypothalamic neuro peptide Y (NPY) (Jahng, 2011).

\section{GENE EXPRESSION}

Many animal studies, including MS, have improved our knowledge of gene-environment interactions and elucidated the pathways that program an animal in response to its early life experiences (Meaney and Szyf, 2005). Epigenetic mechanisms involving DNA methylation, post-translational modification of histone proteins and non-coding RNAs (most notably micro-RNA) are major candidates for regulating gene expression and integrating intrinsic and environmental signals in the genome (Jaenisch and Bird, 2003). Murgatroyd and colleagues showed that in the parvocellular subdivision of the paraventricular nucleus of the hypothalamus, MS in mice persistently upregulates $A v p$ gene expression associated with reduced DNA methylation of a region in the Avp enhancer. This early life stress-responsive region serves as a binding site for the methyl-CpG binding protein 2, which in turn is regulated through neuronal activity. They also found that the ability of methyl-CpG binding protein 2 to control transcription of the Avp gene and induce DNA methylation occurred by recruiting components of the epigenetic machinery (Murgatroyd et al., 2009; Murgatroyd and Nephew, 2013). Other groups investigated DNA methylation levels at a specific sequence motif upstream of the GR gene $(\mathrm{Nr} 3 \mathrm{cl})$ in the hippocampus of offspring, and found that subjecting pups to a single $24 \mathrm{~h}$ MS increases methylation levels (Kember et al., 2012). The epigenetic alterations of these genes suggest that the HPA axis could be dysregulated by MS. Importantly, however, the DNA methylation differences were also often strain specific (Kember et al., 2012). Taken together, these findings demonstrate the importance of investigating environmental effects on a range of genetic backgrounds, emphasizing the need for the further examination of environmental, genetic, and epigenetic interactions.

\section{CONCLUSIONS}

Adverse environments and experiences during the neonatal period can dramatically affect the development of the HPA axis that underlies adaptive behavioral responses. MS experiments, as a model of early life stress, demonstrate that CORT levels and cFos expression change depending upon the different experimental conditions of MS, e.g., age at testing and frequency of repetition. Furthermore, separation conditions (isolation with or without a littermate) could also influence the results of the MS experiments. MS can induce various behavioral changes manifested in later life, 
which could be caused, at least in part, by alterations in gene expression, particularly through epigenetic mechanisms.

\section{ACKNOWLEDGMENTS}

This work was supported by Grants-in-Aid for Scientific Research (23390040 to Mayumi Nishi and AstraZeneca Research Grant 2009). We thank Dr. Julian G. Mercer, a chief editor of J Neuroendocrinology, for permitting the reuse of our own figures published in J Neuroendocrinology.

\section{REFERENCES}

Agid, O., Shapira, B., Zislin, J., Ritsner, M., Hanin, B., Murad, H., et al. (1999). Environment and vulnerability to major psychiatric illness: a case control study of early parental loss in major depression, bipolar disorder and schizophrenia. Mol. Psychiatry 4, 163-172. doi: 10.1038/sj.mp.4000473

Aisa, B., Tordera, R., Lasheras, B., Del Rio, J., and Ramirez, M. J. (2008). Effects of maternal separation on hypothalamic-pituitary-adrenal responses, cognition and vulnerability to stress in adult female rats. Neuroscience 154, 1218-1226. doi: 10.1016/j.neuroscience.2008.05.011

Arborelius, L., and Eklund, M. B. (2007). Both long and brief maternal separation produces persistent changes in tissue levels of brain monoamines in middle-aged female rats. Neuroscience 145, 738-750. doi: 10.1016/j.neuroscience.2006.12.007

Barreau, F., Cartier, C., Ferrier, L., Fioramonti, J., and Bueno, L. (2004). Nerve growth factor mediates alterations of colonic sensitivity and mucosal barrier induced by neonatal stress in rats. Gastroenterology 127, 524-534. doi: 10.1053/j.gastro.2004.05.019

Biagini, G., Pich, E. M., Carani, C., Marrama, P., and Agnati, L. F. (1998). Postnatal maternal separation during the stress hyporesponsive period enhances the adrenocortical response to novelty in adult rats by affecting feedback regulation in the CA1 hippocampal field. Int. J. Dev. Neurosci. 16, 187-197. doi: 10.1016/S0736-5748(98)00019-7

Bremne, J. D., and Vermetten, E. (2001). Stress and development: behavioral and biological consequences. Dev. Psychopathol. 13, 473-489. doi: $10.1017 /$ S0954579401003042

Caldji, C., Diorio, J., and Meaney, M. J. (2000). Variations in maternal care in infancy regulate the development of stress reactivity. Biol. Psychiatry 48, 1164-1174. doi: 10.1016/S0006-3223(00)01084-2

Callaghan, B. L., Graham, B. M., Li, S., and Richardson, R. (2013). From resilience to vulnerability: mechanistic insights into the effects of stress on transitions in critical period plasticity. Front. Psychiatry 4:90. doi: 10.3389/fpsyt.2013.00090

Carrera, O., Cerrato, M., Sanchez, A., and Gutierrez, E. (2009). Long maternal separation has protective effects in rats exposed to activity-based anorexia. Dev. Psychobiol. 51, 616-624. doi: 10.1002/dev.20396

Chocyk, A., Przyborowska, A., Makuch, W., Majcher-Maslanka, I., Dudys, D., and Wedzony, K. (2014). The effects of early-life adversity on fear memories in adolescent rats and their persistence into adulthood. Behav. Brain Res. 264, 161-172. doi: 10.1016/j.bbr.2014.01.040

Daniels, W. M., Pietersen, C. Y., Carstens, M. E., and Stein, D. J. (2004). Maternal separation in rats leads to anxiety-like behavior and a blunted ACTH response and altered neurotransmitter levels in response to a subsequent stressor. Metab. Brain Dis. 19, 3-14. doi: 10.1023/B:MEBR.0000027412.19664.b3

Davis, M., Walker, D. L., Miles, L., and Grillon, C. (2010). Phasic vs sustained fear in rats and humans: role of the extended amygdala in fear vs anxiety. Neuropsychopharmacology 35, 105-135. doi: 10.1038/npp.2009.109

Ellenbroek, B. A., Van Den Kroonenberg, P. T., and Cools, A. R. (1998). The effects of an early stressful life event on sensorimotor gating in adult rats. Schizophr. Res. 30, 251-260. doi: 10.1016/S0920-9964(97)00149-7

Enthoven, L., Oitzl, M. S., Koning, N., Van Der Mark, M., and De Kloet, E. R. (2008). Hypothalamic-pituitary-adrenal axis activity of newborn mice rapidly desensitizes to repeated maternal absence but becomes highly responsive to novelty. Endocrinology 149, 6366-6377. doi: 10.1210/en.2008-0238

Felitti, V. J., Anda, R. F., Nordenberg, D., Williamson, D. F., Spitz, A. M., Edwards, V., et al. (1998). Relationship of childhood abuse and household dysfunction to many of the leading causes of death in adults. The Adverse Childhood Experiences (ACE) study. Am. J. Prev. Med. 14, 245-258. doi: 10.1016/S07493797(98)00017-8
Francis, D. D., Champagne, F. A., Liu, D., and Meaney, M. J. (1999). Maternal care, gene expression, and the development of individual differences in stress reactivity. Ann. N.Y. Acad. Sci. 896, 66-84. doi: 10.1111/j.1749-6632.1999. tb08106.x

Furukawa, T. A., Ogura, A., Hirai, T., Fujihara, S., Kitamura, T., and Takahashi, K. (1999). Early parental separation experiences among patients with bipolar disorder and major depression: a case-control study. J. Affect. Disord. 52, 85-91. doi: 10.1016/S0165-0327(98)00054-8

Glaser, J. P., Van Os, J., Portegijs, P. J., and Myin-Germeys, I. (2006). Childhood trauma and emotional reactivity to daily life stress in adult frequent attenders of general practitioners. J. Psychosom. Res. 61, 229-236. doi: 10.1016/j.jpsychores.2006.04.014

Heim, C., and Nemeroff, C. B. (2001). The role of childhood trauma in the neurobiology of mood and anxiety disorders: preclinical and clinical studies. Biol. Psychiatry 49, 1023-1039. doi: 10.1016/S0006-3223(01)01157-X

Holmes, A., Le Guisquet, A. M., Vogel, E., Millstein, R. A., Leman, S., and Belzung, C. (2005). Early life genetic, epigenetic and environmental factors shaping emotionality in rodents. Neurosci. Biobehav. Rev. 29, 1335-1346. doi: 10.1016/j.neubiorev.2005.04.012

Horii-Hayashi, N., Sasagawa, T., Matsunaga, W., Matsusue, Y., Azuma, C., and Nishi, M. (2013). Developmental changes in desensitisation of c-Fos expression induced by repeated maternal separation in pre-weaned mice. J. Neuroendocrinol. 25, 158-167. doi: 10.1111/j.1365-2826.2012.02377.x

Huot, R. L., Gonzalez, M. E., Ladd, C. O., Thrivikraman, K. V., and Plotsky, P. M. (2004). Foster litters prevent hypothalamic-pituitary-adrenal axis sensitization mediated by neonatal maternal separation. Psychoneuroendocrinology 29, 279-289. doi: 10.1016/S0306-4530(03)00028-3

Huot, R. L., Thrivikraman, K. V., Meaney, M. J., and Plotsky, P. M. (2001). Development of adult ethanol preference and anxiety as a consequence of neonatal maternal separation in Long Evans rats and reversal with antidepressant treatment. Psychopharmacology (Berl.) 158, 366-373. doi: 10.1007/s002130100701

Iwasaki, S., Inoue, K., Kiriike, N., and Hikiji, K. (2000). Effect of maternal separation on feeding behavior of rats in later life. Physiol. Behav. 70, 551-556. doi: 10.1016/S0031-9384(00)00305-X

Jaenisch, R., and Bird, A. (2003). Epigenetic regulation of gene expression: how the genome integrates intrinsic and environmental signals. Nat. Genet. 33(Suppl.), 245-254. doi: 10.1038/ng1089

Jahng, J. W. (2011). An animal model of eating disorders associated with stressful experience in early life. Horm. Behav. 59, 213-220. doi: 10.1016/j.yhbeh.2010.11.010

Jahng, J. W., Ryu, V., Yoo, S. B., Noh, S. J., Kim, J. Y., and Lee, J. H. (2010). Mesolimbic dopaminergic activity responding to acute stress is blunted in adolescent rats that experienced neonatal maternal separation. Neuroscience 171, 144-152. doi: 10.1016/j.neuroscience.2010.08.063

Kalinichev, M., Easterling, K. W., Plotsky, P. M., and Holtzman, S. G. (2002). Long-lasting changes in stress-induced corticosterone response and anxietylike behaviors as a consequence of neonatal maternal separation in LongEvans rats. Pharmacol. Biochem. Behav. 73, 131-140. doi: 10.1016/S0091-3057 (02)00781-5

Kember, R. L., Dempster, E. L., Lee, T. H., Schalkwyk, L. C., Mill, J., and Fernandes, C. (2012). Maternal separation is associated with strain-specific responses to stress and epigenetic alterations to $\mathrm{Nr} 3 \mathrm{cl}, \mathrm{Avp}$, and Nr4a1 in mouse. Brain Behav. 2, 455-467. doi: 10.1002/brb3.69

Kendler, K. S., Neale, M. C., Kessler, R. C., Heath, A. C., and Eaves, L. J. (1992). Childhood parental loss and adult psychopathology in women. A twin study perspective. Arch. Gen. Psychiatry 49, 109-116. doi: 10.1001/archpsyc.1992.01820020029004

Kendler, K. S., Sheth, K., Gardner, C. O., and Prescott, C. A. (2002). Childhood parental loss and risk for first-onset of major depression and alcohol dependence: the time-decay of risk and sex differences. Psychol. Med. 32, 1187-1194. doi: $10.1017 /$ S0033291702006219

Ladd, C. O., Owens, M. J., and Nemeroff, C. B. (1996). Persistent changes in corticotropin-releasing factor neuronal systems induced by maternal deprivation. Endocrinology 137, 1212-1218. doi: 10.1210/en.137.4.1212

Lee, J. H., Kim, H. J., Kim, J. G., Ryu, V., Kim, B. T., Kang, D. W., et al. (2007). Depressive behaviors and decreased expression of serotonin reuptake transporter in rats that experienced neonatal maternal separation. Neurosci. Res. 58, 32-39. doi: 10.1016/j.neures.2007.01.008 
Levine, S. (1967). Maternal and environmental influences on the adrenocortical response to stress in weanling rats. Science 156, 258-260. doi: 10.1126/science.156.3772.258

Levine, S. (2001). Primary social relationships influence the development of the hypothalamic-pituitary-adrenal axis in the rat. Physiol. Behav. 73, 255-260. doi: 10.1016/S0031-9384(01)00496-6

Levine, S. (2005). Developmental determinants of sensitivity and resistance to stress. Psychoneuroendocrinology 30, 939-946. doi: 10.1016/j.psyneuen.2005. 03.013

Lippmann, M., Bress, A., Nemeroff, C. B., Plotsky, P. M., and Monteggia, L. M. (2007). Long-term behavioural and molecular alterations associated with maternal separation in rats. Eur. J. Neurosci. 25, 3091-3098. doi: 10.1111/j.14609568.2007.05522.x

Lyons, D. M., Kim, S., Schatzberg, A. F., and Levine, S. (1998). Postnatal foraging demands alter adrenocortical activity and psychosocial development. Dev. Psychobiol. 32, 285-291. doi: 10.1002/(SICI)1098-2302(199805)32:4<285: AID-DEV3>3.0.CO;2-J

MacMillan, H. L., Fleming, J. E., Streiner, D. L., Lin, E., Boyle, M. H., Jamieson, E., et al. (2001). Childhood abuse and lifetime psychopathology in a community sample. Am. J. Psychiatry 158, 1878-1883. doi: 10.1176/appi.ajp.158.11.1878

Marais, L., Van Rensburg, S. J., Van Zyl, J. M., Stein, D. J., and Daniels, W. M. (2008). Maternal separation of rat pups increases the risk of developing depressive-like behavior after subsequent chronic stress by altering corticosterone and neurotrophin levels in the hippocampus. Neurosci. Res. 61, 106-112. doi: 10.1016/j.neures.2008.01.011

McCormick, C. M., Kehoe, P., and Kovacs, S. (1998). Corticosterone release in response to repeated, short episodes of neonatal isolation: evidence of sensitization. Int. J. Dev. Neurosci. 16, 175-185. doi: 10.1016/S0736-5748(98)00026-4

Meaney, M. J. (2001). Maternal care, gene expression, and the transmission of individual differences in stress reactivity across generations. Annu. Rev. Neurosci. 24, 1161-1192. doi: 10.1146/annurev.neuro.24.1.1161

Meaney, M. J., and Szyf, M. (2005). Maternal care as a model for experiencedependent chromatin plasticity? Trends Neurosci. 28, 456-463. doi: 10.1016/j.tins.2005.07.006

Menard, J. L., Champagne, D. L., and Meaney, M. J. (2004). Variations of maternal care differentially influence "fear" reactivity and regional patterns of cFos immunoreactivity in response to the shock-probe burying test. Neuroscience 129, 297-308. doi: 10.1016/j.neuroscience.2004.08.009

Miyazaki, T., Takase, K., Nakajima, W., Tada, H., Ohya, D., Sano, A., et al. (2012). Disrupted cortical function underlies behavior dysfunction due to social isolation. J. Clin. Invest. 122, 2690-2701. doi: 10.1172/JCI63060

Morgan, C., Kirkbride, J., Leff, J., Craig, T., Hutchinson, G., McKenzie, K., et al. (2007). Parental separation, loss and psychosis in different ethnic groups: a case-control study. Psychol. Med. 37, 495-503. doi: 10.1017/S003329170 6009330

Murgatroyd, C., Patchev, A. V., Wu, Y., Micale, V., Bockmuhl, Y., Fischer, D., et al. (2009). Dynamic DNA methylation programs persistent adverse effects of earlylife stress. Nat. Neurosci. 12, 1559-1566. doi: 10.1038/nn.2436

Murgatroyd, C. A., and Nephew, B. C. (2013). Effects of early life social stress on maternal behavior and neuroendocrinology. Psychoneuroendocrinology 38, 219-228. doi: 10.1016/j.psyneuen.2012.05.020

Newport, D. J., Stowe, Z. N., and Nemeroff, C. B. (2002). Parental depression: animal models of an adverse life event. Am. J. Psychiatry 159, 1265-1283. doi: 10.1176/appi.ajp.159.8.1265

Nishi, M., Horii-Hayashi, N., Sasagawa, T., and Matsunaga, W. (2013). Effects of early life stress on brain activity: implications from maternal separation model in rodents. Gen. Comp. Endocrinol. 181, 306-309. doi: 10.1016/j.ygcen.2012.09.024

Noh, S. J., Ryu, V., Yoo, S. B., Lee, J. H., Min, B. M., and Jahng, J. W. (2008). Suppressed intake of highly palatable food and dysfunctional of HPA axis response to restraint stress in adolescent rats that experienced neonatal maternal separation. Appetite 51:388. doi: 10.1016/j.appet.2008.04.174
Plotsky, P. M., Thrivikraman, K. V., Nemeroff, C. B., Caldji, C., Sharma, S., and Meaney, M. J. (2005). Long-term consequences of neonatal rearing on central corticotropin-releasing factor systems in adult male rat offspring. Neuropsychopharmacology 30, 2192-2204. doi: 10.1038/sj.npp.1300769

Pryce, C. R., Ruedi-Bettschen, D., Dettling, A. C., Weston, A., Russig, H., Ferger, B., et al. (2005). Long-term effects of early-life environmental manipulations in rodents and primates: potential animal models in depression research. Neurosci. Biobehav. Rev. 29, 649-674. doi: 10.1016/j.neubiorev.2005.03.011

Rosenfeld, P., Gutierrez, Y. A., Martin, A. M., Mallett, H. A., Alleva, E., and Levine, S. (1991). Maternal regulation of the adrenocortical response in preweanling rats. Physiol. Behav. 50, 661-671. doi: 10.1016/0031-9384(91)90001-5

Ryu, V., Lee, J. H., Yoo, S. B., Gu, X. F., Moon, Y. W., and Jahng, J. W. (2008). Sustained hyperphagia in adolescent rats that experienced neonatal maternal separation. Int. J. Obes. (Lond.) 32, 1355-1362. doi: 10.1038/ijo.2008.108

Ryu, V., Yoo, S. B., Kang, D. W., Lee, J. H., and Jahng, J. W. (2009). Postweaning isolation promotes food intake and body weight gain in rats that experienced neonatal maternal separation. Brain Res. 1295, 127-134. doi: 10.1016/j.brainres.2009.08.006

Sapolsky, R. M. (1996). Stress, glucocorticoids, and damage to the nervous System: the current state of confusion. Stress 1, 1-19. doi: 10.3109/10253899609 001092

Sapolsky, R. M., and Meaney, M. J. (1986). Maturation of the adrenocortical stress response: neuroendocrine control mechanisms and the stress hyporesponsive period. Brain Res. 396, 64-76. doi: 10.1016/0165-0173(86)90010-X

Smith, P. M., and Ferguson, A. V. (2010). Circulating signals as critical regulators of autonomic state-central roles for the subfornical organ. Am. J. Physiol. Regul. Integr. Comp. Physiol. 299, R405-R415. doi: 10.1152/ajpregu.00103.2010

Stein, M. B., Walker, J. R., Anderson, G., Hazen, A. L., Ross, C. A., Eldridge, G., et al. (1996). Childhood physical and sexual abuse in patients with anxiety disorders and in a community sample. Am. J. Psychiatry 153, 275-277.

Teicher, M. H., Tomoda, A., and Andersen, S. L. (2006). Neurobiological consequences of early stress and childhood maltreatment: are results from human and animal studies comparable? Ann. N.Y. Acad. Sci. 1071, 313-323. doi: 10.1196/annals.1364.024

Tjong, Y. W., Ip, S. P., Lao, L., Wu, J., Fong, H. H., Sung, J. J., et al. (2010). Neonatal maternal separation elevates thalamic corticotrophin releasing factor type 1 receptor expression response to colonic distension in rat. Neuro Endocrinol. Lett. 31, 215-220.

Vazquez, D. M., Lopez, J. F., Van Hoers, H., Watson, S. J., and Levine, S. (2000). Maternal deprivation regulates serotonin $1 \mathrm{~A}$ and $2 \mathrm{~A}$ receptors in the infant rat. Brain Res. 855, 76-82. doi: 10.1016/S0006-8993(99)02307-0

Walker, C. D., Scribner, K. A., Cascio, C. S., and Dallman, M. F. (1991). The pituitary-adrenocortical system of neonatal rats is responsive to stress throughout development in a time-dependent and stressor-specific fashion. Endocrinology 128, 1385-1395. doi: 10.1210/endo-128-3-1385

Conflict of Interest Statement: The authors declare that the research was conducted in the absence of any commercial or financial relationships that could be construed as a potential conflict of interest.

Received: 24 February 2014; accepted: 30 May 2014; published online: 17 June 2014. Citation: Nishi M, Horii-Hayashi N and Sasagawa T (2014) Effects of early life adverse experiences on the brain: implications from maternal separation models in rodents. Front. Neurosci. 8:166. doi: 10.3389/fnins.2014.00166

This article was submitted to Neuroendocrine Science, a section of the journal Frontiers in Neuroscience.

Copyright (C) 2014 Nishi, Horii-Hayashi and Sasagawa. This is an open-access article distributed under the terms of the Creative Commons Attribution License (CC BY). The use, distribution or reproduction in other forums is permitted, provided the original author(s) or licensor are credited and that the original publication in this journal is cited, in accordance with accepted academic practice. No use, distribution or reproduction is permitted which does not comply with these terms. 